\title{
Analysis of the Impact of Social Marketing on the Reduction of Seroprevalence of Infection in Mali: Case of the NGO Wale in the Urban Commune of Ségou
}

\author{
Salia TRAORE KONE Abdrahamane \\ Université des Sciences Sociales et gestion Bamako Mali \\ Bamako Mali
}

\begin{abstract}
This work aims to assess the importance of social marketing through communication in reducing the seroprevalence of HIV infection in the urban commune of Ségou. This analysis, based on both theoretical and empirical studies, involved a sample of one hundred and five (100) people made up of residents of the urban commune of Ségou and staff of the NGO Walé. The results of our research "The impact of social marketing on reducing hiv infection in Mali" show that the majority of respondents in the urban commune of Ségou (81\%) are satisfied with the means of communication of social marketing to reduce the seroprevalence of HIV infection against $19 \%$ of unsusc satisfied for various reasons (4\% due to the always high rate, $9 \%$ of cases of denial and $6 \%$ who find communication strategies insufficient).Of $81 \%$ of people who are satisfied with the means of social marketing communication used to reduce the seroprevalence of HIV/AIDS, $49 \%$ are men compared to $32 \%$ of women. Our results show that the use of social marketing techniques has a positive impact on the reduction of seroprevalence in the urban commune of Ségou.
\end{abstract}

Keywords: social marketing, seroprevalence reduction, infection

DOI: $10.7176 / \mathrm{EJBM} / 12-36-03$

Publication date: December $31^{\text {st }} 2020$

\section{Introduction:}

The HIV pandemic is a scourge that affects every continent and whose poverty contributes greatly to progress. With more than 35 million deaths to date, HIV continues to be a major global public health problem.

In 2014, an estimated 34.3 to 41.4 million people were living with HIV worldwide. There has been an increase over previous years as a result of the increase in the number of people on antiretroviral therapy.

According to the WHO at the end of 2017, between 31.1 and 43.9 million people were living with HIV/AIDS today. As many as 1.8 million new cases are reported each year. Since the early $1980 \mathrm{~s}$, the disease has reportedly killed nearly 35 million people.

of new infections with the virus worldwide, in sub-Saharan Africa, three out of four new infections affect girls aged 15 to 19 , and young women aged 15 to 24 are twice as likely to live with HIV as men.

In Mali, although its impact on the national economy is not assessed, HIV AIDS is an obstacle to economic development through the financial effects of its care and its social impact on communities. Its prevalence among the population aged 15 to 49 rose from $1.7 \%$ in 2001 to $1.1 \%$ in 2017 with disparities depending on the level of residence $(1.9 \%$ in urban areas versus $0.9 \%$ in rural areas) and gender. The prevalence rate is higher for women than for men, at $1.3 \%$ and $0.8 \%$ respectively.

Unfortunately, these results highlight a reality that seriously hampers the fight against the disease. They demonstrate the weakness of the national response, which still depends heavily on $(80 \%)$ external funding. The definition of the role of each actor (Ministry of Health and civil society) is also essential for a better national appropriation of this struggle. HIV pandemic is a scourge that affects every continent and.

However, the effectiveness of all these responses will lie in the use of appropriate social marketing management tools in the fight against AIDS. This leads us to reflect and ask the following question: How important social marketing is in reducing the seroprevalence of HIV infection.

To add to this problem, this paper will be organized as follows: The first will be devoted to the contextual framework, the literature and methodological review and the second part we will present the results and the conclusion.

\subsection{Literature Review}

\subsubsection{History:}

Marketing has its roots in religion, politics, education and, to some extent, military strategy. It also uses intellectual disciplines such as psychology, sociology, political science, communication theory and anthropology. When marketing becomes social when it serves associations, the promotion of ideas and causes of public interest. Before we understand the concept in its contours, we will look at its historical foundations.

Social marketing is an ancient concept at the heart of the processes planned to bring about change. The 
individual has always tried to inform, persuade, influence, motivate, and gain the trust of new adherents to a set of ideas. In its broadest sense, social marketing is therefore a new approach to designing very old human projects. According to Kotler, advertising campaigns to promote social progress are not a new phenomenon. In GrecoRoman antiquity, campaigns were recorded to call for the liberation of slaves. During the industrial revolution, English civil society organized campaigns against incarceration for debt and child labour, as well as for women's right to vote. In the 19th century, the United States was agitated by movements for the abolition of slavery. Other movements such as the suffragette have led to the implementation of important social reforms.

Consumer advocacy campaigns have forced governments to regulate the quality of food and medicines.

It was in 1971 that Kotler and Zaltman3 first used the concept of social marketing. Although the idea dates back to January 1969 in an article in the Journal of Marketing where Kotler and Lévy suggested expanding the application of the concept of commercial marketing to social causes: "Marketing is a human activity oriented towards the satisfaction of desires through exchange. The societal marketing perspective is a management orientation geared towards customer satisfaction and the long-term well-being of the consumer and the general public as a means of enabling the organization to achieve its objectives and meet its responsibilities."

"These authors did not propose a new concept; rather, they aimed to bring into the concerns of theorists a practice that was taking place at that time, since museums, hospitals, politicians, or even, in developing countries especially, the promotion of birth control were being promoted."

It must be said that the emergence of the concept of social marketing did not please everyone. Theorists and social workers are protesting against this expansion of the field of commercial marketing. The latter has rather bad press in that it would use 'deception' towards consumers. Ideas are "noble" entities. "You can produce goods and adapt them to the tastes of others for profit; to do the same with ideas will be seen as demagoguery, deceit, even prostitution." But this conception of things did not prevail and social marketing took off brilliantly. Today, it is used in several areas: health promotion, environmental protection, education, economics, domestic violence, human rights, racism, etc.

But what does the concept of social marketing cover? Social marketing uses commercial marketing techniques to solve social problems that are essentially based on behavioural change. According to Philip Kotler, social marketing is the design, implementation and control of programs designed to promote a social idea or practice to a target group. It is $<<$ a social change management technique that includes the design, implementation and control of programs to increase the acceptability of an idea or action to one or more target groups." According to Andreasen, social marketing implements "the analysis, planning, delivery and evaluation of programs designed to influence the voluntary behaviour of the target audience to improve their well-being and that of society."

Social marketing aims to influence and change social behaviour for the benefit of the target audience and society at large. It's within everyone's reach. It has nothing to do with education insofar as its ultimate goal is to influence behaviour. It may seek to change values and attitudes to influence behaviour. Social marketing recognizes many of the principles that apply to commercial marketing: assessing needs, identifying the target audience, developing products, and evaluating results. According to Kotler, social marketing $<<$ usus the concepts of market segmentation, consumer research, development, communication, facilitation, stimulating and exchange theory to maximize the response of the target group."

Commercial marketing is based on competition between companies while social marketing gives precedence to the well-being of its customers. Acting on behalf of the community, it is based not on desires, but the values and ideals of society; it is above all the marketing of the good. When commercial marketing plays on the pleasure of the smoker by offering him longer and tastier cigarettes, social marketing will engage him, in the name of a certain value, not to smoke. The success of social marketing is measured, not in terms of money, but in terms of qualitative change of the individual where society rediscovers its roots, its values, its humanism.

\subsubsection{Review of previous studies on the subject}

Reducing the seroprevalence of HIV infection has been the subject of much research because of the importance of HIV infection.

Studies in many countries have shown that many factors are involved in the spread of HIV.

Discovered in the United States in 1983, the Human Immunodeficiency Virus (HIV) is now one of the world's greatest murderers. More than twenty-three million deaths worldwide are directly attributable to it, of which nineteen million are in sub-Saharan Africa alone; it is also in this part of the world that more than two-thirds of the 33 million people living with the virus reside (UNAIDS, 2008). In addition to this already alarming picture, the effects of the disease do not stop in the medical field.

Beyond the health sector, what makes HIV/AIDS special is its impact on development. Indeed, the disease affects adults in their most sexually active years that coincide with their most productive years. Without HIV/AIDS, these people would have little chance of dying from another cause.

For example, HIV/AIDS affects development by:

1- The symptoms of the disease were discovered in the first subjects in 1981, the name AIDS was adopted in 1982 , but it was not until 1983 that the virus responsible for AIDS could be identified. 
2- Before the HIV/AIDS epidemic, mortality in sub-Saharan Africa was mainly concentrated in the 0-5 age groups due to infant and over-50 mortality.

after age 50 and therefore does not affect the age group of people counted in the HIV/AIDS prevalence rate) which account for $9 \%$ of deaths, malignancies, and diabetes with $3.5 \%$ and less than $1 \%$ of total deaths, respectively. The labor intermediary is the key factor in production in Africa. Through it, disease undermines three pillars of development: economic growth, human capital, and the investment climate. Macroeconomic calculations have assessed the impact of AIDS on the economies of developing countries: one to two points of GDP growth (gross domestic product) is lost when 10\% of the population is infected (Couderc and Ventelou, 2005).

This is huge for a continent where half the population lives below the poverty line and which must achieve an economic growth rate of $5 \%$ per year just to maintain the status quo. HIV/AIDS exacerbates poverty and contributes to growing inequalities between the developed and developing worlds. The consequences of HIV/AIDS on development are undeniable, so it must be seen as a development problem in its own right. Currently, there is no vaccine for HIV/AIDS, and the most effective treatments that involve ART of antiretroviral drugs are inaccessible to the vast majority of the groups most at risk of infection. This means that the only effective way to combat the evolution of the epidemic for these countries is through prevention. The purpose of this article is precise to identify the various factors that influence or could influence the spread of HIV/AIDS, as well as the different channels through which this impact passes, particularly in sub-Saharan Africa. The HIV/AIDS epidemic is driven by a range of socio-economic, socio-cultural, and epidemiological determinants. These determinants are numerous, complex, interact with each other, and have a double causal link with the HIV/AIDS epidemic. This is precisely one of the reasons why the epidemic has evolved worse than even in the most pessimistic projections.

Indeed, the epidemic is spreading because economic, socio-cultural, and epidemiological conditions favor it. In turn, as described above, it aggravates these conditions, notably through its impact on the workforce, institutions, and even diseases. This leads to a vicious cycle of the HIV/AIDS epidemic in poor countries. While much work has been devoted to the economics of HIV/AIDS over the past decade, most of it consists of impact studies and assessments of the impact of the epidemic on various aspects of economic life. The analysis of the determinants of the epidemic seems equally relevant to us. Although the resources allocated to the fight against HIV/AIDS are far from sufficient, much could already be done from such an amount to control the epidemic provided that resources are allocated where they are used in the most effective way.

The Importance of the Environment In September 1999, UNAIDS 6 conducted a study to explain the difference in the rates of spread of the HIV/AIDS epidemic in Central and West Africa (where prevalence was relatively low) and in East and Southern Africa (where prevalence was much higher). This study found that differences in behavior alone are not sufficient to explain differences in HIV prevalence rates. Behavioral differences even seem to be more than offset by differences in the risk of transmission of the virus. Although the median age at first sexual intercourse was lower in southern and eastern Africa and the age difference between partners is greater than in Central and West Africa, changes in partners and male contact with sex workers were more common in Central and West Africa than in southern and eastern Africa. Condom use during casual contact was low at all sites. On the other hand, with the exception of chlamydia, communicable sexual diseases were much more common at the sites of Kisumu (Kenya) and Ndola (Zambia) than in Cotonou (Benin) and Yaounde (Cameroon). Moreover, in Cotonou and Yaounde, virtually all men reported being circumcised, compared to only $10 \%$ in Ndola and less than $30 \%$ in Kisumu.

Stillwagon (2000) agrees as it is wary of the "exceptional nation" of the African HIV/AIDS epidemic. For her, it is important to focus on sanitary and economic conditions when studying the determinants of the epidemic. Thus, gender discrimination, malnutrition, and parasitosis, lack of hygiene and care for STIs are of the utmost importance, especially as these characteristics are also found in other parts of the world facing an emerging HIV/AIDS epidemic.

Finally, Bonnel (2000) points to the political-legal climate as one of the catalysts for the epidemic, which is at the same time a variable on which HIV will have a negative impact. In most countries facing a widespread epidemic, the spread of HIV/AIDS goes hand in hand with high rates of poverty and therefore deplorable living conditions, high income and gender inequalities, incomplete epidemiological transition resulting in the high prevalence of infectious diseases, and still inadequate knowledge of the epidemic (UNDP, 2003).

For example, in the implementation of prevention programs, social marketing tools such as Information, Education and Communication Strategies (IEC) and Communication for Behavioural Change (CCC) are generally used.

What should be these social marketing tools to reduce the seroprevalence of HIV infection in the Walé NGO area of intervention?

\subsection{Methodology}

\subsubsection{Study area}

Our study took place at the NGO Walé "action-health-population" in Ségou, which is located in the Angoulême 
district (in its own premises), in the urban commune of Ségou, Ségou region in the Republic of Mali.

\subsubsection{Choice criteria}

Since its creation in June 1997, the NGO Walé has continued to work to become a reference institution, professional and credible by the quality of its interventions in the implementation of sectoral health and social development policies at the level of the Ségou and national region.

Since then, it has made efforts to develop and support information, training, education, and communication to improve people's living environment; assist groups, communities, communities, public authorities, and any other individuals or institutions interested in improving health. It supports the socio-economic promotion of target groups affected by health problems such as people living with HIV/AIDS.

Thus, after several years of an operation aimed at improving the health status of populations in its areas of intervention and particularly in the field of HIV/AIDS, this work aims to assess the importance of communication in reducing the seroprevalence of HIV infection in the urban commune of Ségou.

\subsection{Study type}

This is a two-pronged cross-sectional study: quantitative and qualitative

As such, the following methods have been combined:

The documentary review: covered documents from the NGO Walé as well as previous studies on HIV infection (EDS v Mali; EDS 2010 Burundi; Doctor DRAME, A (2013) Abidjan; THE DETERMINANTS OF THE HIV/AIDS EPIDEMIC IN SUB-SAHARAN AFRICA, ETC.)

The quantitative survey: looked at indicators of knowledge of HIV infection, means of prevention, and modes of transmission;

The qualitative survey: it consisted of conducting an opinion poll among the populations of the urban commune of Ségou and the staff of the NGO Wale to assess their knowledge of HIV infection and the relevance of the communication strategies implemented by the NGO Wale to reduce the seroprevalence of HIV infection.

Collecting information through a preconceived maintenance guide has this effect.

\subsection{Study population}

$\checkmark \quad$ The study population consisted of:

$\checkmark$ Residents of the urban commune of Ségou;

Staff from the NGO Walé de Ségou.

\subsection{Sample}

\subsubsection{Sampling method}

We used two sampling methods: a probabilistic method for the inhabitants of the urban commune of Ségou and a non-probabilistic and non-exhaustive method for the staff of the NGO Walé.

\subsubsection{Sampling techniques}

\subsubsection{Simple Random Choice}

We went around the urban commune of Ségou to administer our pre-designed questionnaire for this purpose to the inhabitants of the urban commune of Ségou at random until we obtained one hundred (100) people and this without handing over.

\subsubsection{Reasoned Choice}

This technique was used for walé NGO staff.

\subsection{Sample size}

The sample size was set at:

$\checkmark$ Cent (100) for the inhabitants of the Urban Municipality of Ségou and;

$\checkmark \quad$ Two (2) for walé NGO staff.

\subsection{Data collection technique and tools}

\subsubsection{The technique used}

The technique used was the individual interview through our pre-designed questionnaire for this purpose.

\subsubsection{Data Collection Tools}

We used two collection tools:

$\checkmark \quad$ A questionnaire for the inhabitants of the urban commune of Ségou and;

$\checkmark \quad$ A maintenance guide for NGO-Walé staff.

\subsection{Study variables}

The study variables are mainly: gender, age, occupation, education level, residency, knowledge of the existence of HIV, misconceptions about HIV infection, knowledge of how HIV infection is transmitted, knowledge of ways 
to prevent HIV infection, knowledge of the possibility of mother-to-child transmission of HIV infection, knowledge of the existence of a therapeutic method that can prevent mother-to-child transmission of HIV infection, knowledge of a place where HIV/AIDS can be tested, HIV/AIDS testing, educating young people about condom use to protect them against HIV/AIDS, prevention methods used against HIV infection, satisfaction with the means of communication to reduce the seroprevalence of HIV infection, the number of people detected and followed as of December 31, 2017.

\subsection{Data entry and analysis}

Data analysis was the essential method for assessing the importance of communication in reducing the seroprevalence of HIV/AIDS infection in the urban commune of Ségou.

First, manual processing (stripping, cleaning, and coding) of the data was carried out.

The following software was used for the development of the input mask, the capture, and analysis of the data: SPSS 18F (Statistical Package for the Social Sciences version 18 for windows), WORD and EXCEL for windows.

\subsection{Research hypotheses}

Good communication facilitates prevention against HIV infection (abstinence, fidelity, condom use);

Good communication promotes a better understanding of HIV infection, prevention methods, and modes of transmission;

Good communication reduces HIV seroprevalence.

\subsection{Results}

\subsubsection{Socio-demographic characteristics:}

Table I: Breakdown of respondents from the urban commune of Ségou by gender

\begin{tabular}{|l|l|l|}
\hline \multirow{2}{*}{ SEX } & Investigated from the urban commune of Ségou \\
\cline { 2 - 3 } & Effective & Percentage \\
\hline male & $\mathbf{6 2}$ & $\mathbf{6 2 \%}$ \\
\hline Female & 38 & $38 \%$ \\
\hline Total & $\mathbf{1 0 0}$ & $\mathbf{1 0 0 \%}$ \\
\hline
\end{tabular}

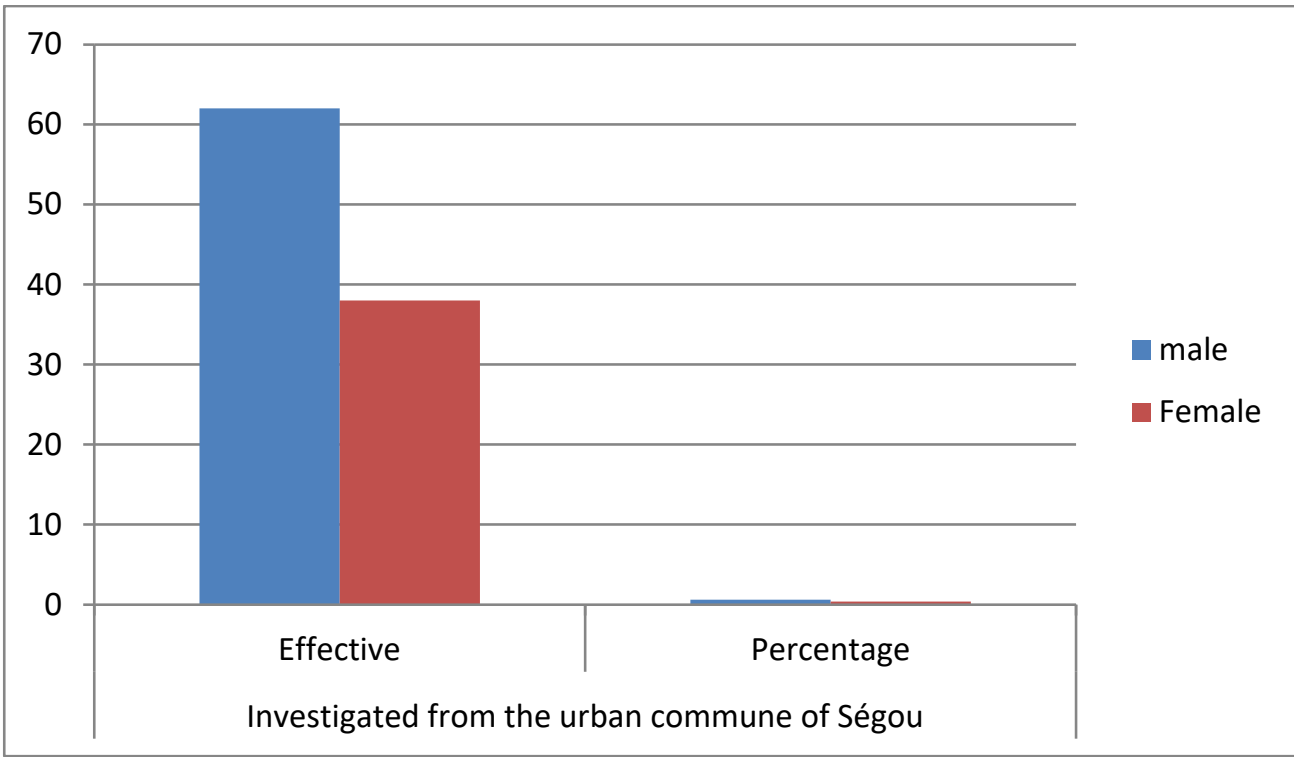

Chart I: Representation of respondents from the urban commune of Ségou by gender

The male sex was the most represented among respondents in the urban commune of Ségou with $62 \%$ against $38 \%$ of women.

\subsection{Analysis and comments}

We wanted to comment and discuss in the following pattern:

\subsubsection{The difficulties of the study}

During our study, despite good will, we faced difficulties that are of various natures:

For the respondents of the urban commune of Ségou, we were confronted with their unavailability because of their daily occupations, and the outright refusal of some to answer our questionnaire for various reasons. 


\subsubsection{Sociodemographic Characteristics}

$\rightarrow$ the study population is more male $(62 \%$ male) than the general population of the urban commune of Ségou $50.05 \%$ male according to RGPH 2009. This difference can be explained by the fact that men have been much more available and open to answering our questionnaire during our visit than women.

$\rightarrow$ the 18-27 age group was the most represented among respondents in the urban commune of Ségou, with $49 \%$. This may be because young people are very interested in HIV/AIDS issues to better protect themselves against this pandemic than adults.

According to EDS-Burundi 2010, HIV prevalence among young people aged 15 to 24 is more than three times higher among urban youth (1.4\%) young people living in rural areas $(0.4 \%)$. It is, therefore, necessary to intensify more advanced communication actions for this age group to better reduce HIV seroprevalence.

\subsubsection{Communication for knowledge of HIV infection, modes of transmission and prevention}

$\rightarrow 62 \%$ of men compared to $38 \%$ of women surveyed in the urban commune of Ségou are aware of HIV/AIDS.

$\rightarrow$ This result is not consistent with that of EDSM V, which finds that the level of knowledge of HIV/AIDS is high in Mali with $83 \%$ of women and $96 \%$ of men. This difference can be explained by the size of the sample.

$\rightarrow$ However, all of these studies have found that men are more familiar with HIV than women. According to a study carried out by Abibata DRAME in Ivory Coast in 2013, the female sex is subject to the rapid spread of HIV infection unlike the male sex whose circumcision can help avoid infection hence the need for communication actions so that the rate of HIV awareness of women can equal or exceed that of men .

$\rightarrow 4 \%$ of high school students have misconceptions about contracting HIV by sharing food with someone with AIDS compared to $0 \%$ of literate people and $1 \%$ of those without education. In total, $10 \%$ of surveys in the urban commune of Ségou have misconceptions about contracting HIV by sharing food with someone with AIDS.

This finding shows that misconceptions about HIV are not a function of the level of education, hence the need for increased awareness-raising activities on the subject to reduce stigma against people living with HIV.

According to EDSM V, the stigmatization rate against people living with HIV is $12 \%$ in urban areas.

$\rightarrow$ The majority of respondents in the urban commune of Ségou have a correct knowledge of the modes of transmission of HIV infection: $89 \%$ (male: $57 \%$ and women: $32 \%$ ) compared to $11 \%$ who do not know about how HIV infection is transmitted.

This result shows that respondents in the urban commune of Ségou know the modes of HIV transmission that can help them better protect themselves against this pandemic. According to EDSM V, men are more likely than women to have proper knowledge of HIV/AIDS transmission.

$\rightarrow$ The $81 \%$ (male: $50 \%$ and female: $31 \%$ ) respondents in the urban commune of Ségou know that HIV infection can be transmitted from mother to child, compared to $18 \%$ who say it is not transmissible by this route and $1 \%$ who have no idea about it. Although women are the first to be affected, their knowledge of the issue is low compared to men. In this context, women must be our priority target audience in our communication efforts on preventing mother-to-child transmission of HIV.

\subsubsection{Communication related to adherence to HIV prevention (abstinence, fidelity, condom use)}

$\rightarrow$ The majority of respondents in the urban commune of Ségou $(95 \%)$ use a means of prevention against HIV infection with a maximum of $55 \%$ who opted for condom use against a minimum of $11 \%$ for abstinence. However, $5 \%$ of respondents do not see any means of prevention against HIV infection.

Although the majority of respondents say they use a means of prevention against HIV infection but the 5\% who do not use any means are not to be overlooked.

\subsubsection{Satisfaction of populations on the means of communication implemented to reduce HIV} seroprevalence

$\rightarrow$ The majority of respondents in the urban commune of Ségou (81\%) are satisfied with the means of communication to reduce the seroprevalence of HIV infection compared to $19 \%$ of census satisfied for various reasons ( $4 \%$ due to the still-high rate, $9 \%$ of cases of denial and $6 \%$ who find communication strategies insufficient).

\section{Conclusion}

The results of our research "The impact of social marketing on reducing HIV infection in Mali" show that the majority of respondents in the urban commune of Ségou (81\%) are satisfied with the means of communication of social marketing to reduce the seroprevalence of HIV infection against $19 \%$ of census satisfied for various reasons ( $4 \%$ due to the always high rate, $9 \%$ of cases of denial and $6 \%$ who find communication strategies insufficient). Of $81 \%$ of people who are satisfied with the means of social marketing communication used to reduce the seroprevalence of HIV/AIDS, $49 \%$ are men compared to $32 \%$ of women.

This research has allowed us to:

Assess people's knowledge of the existence of HIV, how HIV infection is transmitted, and how to prevent HIV infection;

Measuring the level of public satisfaction with the means of communication of social marketing implemented to 
reduce HIV seroprevalence;

Make proposals.

The results of this research show us that social marketing in general and communication in particular have an important role to play in reducing seroprevalence in Mali.

Our results show that the use of social marketing techniques has a positive impact on the reduction of seroprevalence in the urban commune of Ségou.

We believe that the success of the use of social marketing techniques in the fight against HIV/AIDS can be widespread in the fight against other pandemics such as COVID19 in Mali.

We believe that the success of the use of social marketing in the fight against HIV/AIDS can be widespread in the fight against other pandemics such as COVID19.

\section{BIBLIOGRAPHIE}

1. Charron, Danielle, Une introduction à la communication, coll. Communication et société, Presse de l'Université de Québec, 1989.

2. De Bonville, Jean, Le développement historique de la communication publique au Québec, in Communication publique et société, repères pour la réflexion et l'action, coll. dirigée par Michel Beauchamp, éd. Gaëtan Morin, Québec, 1991.

3. De Guise, Jacques, $<<$ Communication publique et changement d'attitude $>>$, in communication publique et société, repères pour la réflexion et l'action, sous la direction de Michel Beauchamp, éd. Gaëtan Morin, Québec, 1991.

4. De Guise, Jacques, $<<$ Le marketing social $>>$ in Communication et société, repères pour la réflexion et l'action, sous la direction de Michel Beauchamp, éd. Gaëtan Morin, Québec, 1991.

5. Demont, L. et all, Communication des entreprises, stratégies et pratiques, Nathan, 1999.

6. Kotler et Dubois, Marketing et Management, $11^{\mathrm{e}}$ édition, Nouveaux Horizons, Paris, 2003.

7. Lazar, Judith, Sociologie de la communication de masse, éd Armand Colin, Paris, 1991.

8. Le Net, Michel, Communication publique, pratique des campagnes d'information, La documentation française, Notes et études documentaires n4977, Paris, 1993.

9. Lendrevie, J., Lévy, J., Lindon, D., Mercator, $8^{\mathrm{e}}$ édition, Dunod, Paris, 2006 Strategor, 4 édition, Dunod, Paris, 2005

10. Tremblay, Gaëtan, $<<$ L'opinion publique $>>$, in Communication publique et société, repères pour la réflexion et l'action, sous la direction de Michel Beauchamp, éd. Gaëtan Morin, Québec, 1991.

11. Adkins, Sue, (1999).Cause Related Marketing - Who Cares Wins. Oxford, UK

12. Andreasen, Alan (1995). Marketing Social Change: Changing Behavior to promote Health, Social Development, and the Environment. San Francisco: Jossey-Bass.

13. Bloom, Paul N. and Gregory T. Gundlach, eds. (2001). Handbook of Marketing and Society. Thousand Oaks, ÇA: Sage.

14. Cause-Related Marketing: Partnership Guidelines and Case Studies. Business for Social Responsibility Education Fund (1999).

15. Drumwright, Minette E. (1996). Company Advertising With a Social Dimension. Cambridge, MA: Marketing Science Institute.

16. Drumwright, M.E and P. Murphy (2000). "Corporate Societal Marketing," in The Handbook of Social Marketing and Society, P.N. Bloom and G.T. Gundlach (eds), Sage Publications: Newbury Park ÇA.

17. Earle, Richard (2000). The Art of Cause Marketing: How to Use Advertising to Change Personal Behavior and Public Policy. NTC Publishing Group.

18. Embley, L Laurence (1992). Doing Well while Doing Good: The Marketing Link between Business and Nonprofit Causes. Prentice Hall PTR.

19. Fine, Seymour H. (1992). Marketing the Public Sector: Promoting the Causes of Public and Non-profit Agendas. Transaction Publishers.

20. Goldberg, Marvin, Martin Fishbein, and Susan Middlestadt, eds. (1997). Social Marketing: Theoretical and Practical Perspectives. Mahwah, N.J.: Lawrence Erlbaum Associates.

21. Harvey, Philip D. (1999). Let Every Child Be Wanted: How Social Marketing is Revolutionizing Contraceptive Use. Westport, Conn., Auburn House.

22. Hastings G,B. and B. Elliott B (1993). Social Marketing Practice in Traffic Safety. Chapter III in Marketing of Traffic Safety. Paris: OECD, 35-53.

23. Kotler, Philip and Armstrong, Principles of Social Marketing.

24. Kotler, Philip and Eduardo Roberto (1989). Social Marketing: Stratégies for Changing Public Behavior. New York: Free Press.

25. Kotler, Philip, Ned Roberto \& Nancy Lee (2002). Social Marketing: Improving the Quality of Life. Thousand Oaks, ÇA; Sage Publishing. 
26. Lovelock, Christopher H. and Charles B. Weinberg (1989). Public and Nonprofit Marketing. Redwood City, ÇA: Scientific Press.

27. MacFadyen, L., Stead M. and G.B. Hastings GB (1999). Social Marketing. Chapter 25 in Baker M.J. (ed), The Marketing Book, 4th édition. Oxford: Butterworth Heinemann.

28. Mann, C., Social Marketing Manual, disponible sur Internet, URL: http://oak.cats.ohiou.edu/ cml30791/social/social.htm

29. Marconi, Joe (2002). Cause Marketing: Build Your Image Through Socially Responsible Partnerships, Programs and Events. Dearborn Trade Publishing.

30. McKenzie-Mohr, Doug, and William Smith (1999). Fostering Sustainable Behavior: An Introduction to Community-Based Social Marketing. New Society Pub.

31. Pringle, Harnish and Mariorie Thompson (2001). Brand Spirit: How Cause Related Builds Brads. Wiley, John \& Sons, Inc.

32. Salmon, Charles, T. (1969). Information Campaigns: Balancing Social Values and Social Change. Newbury Park, CA: Sage Publications, Inc.

33. Singhal, Arvind, and Everett M. Rogers (1999). Entertainment-Education : A Communication Strategy for Social Change (Lea's Communication Séries). Lawrence Erlbaum Assoc.

34. Steckel, Richard and Robin Simons (1992). Doing Best by Doing Good. New York: Penguin Books.

35. Stern. GJ. (1994). Marketing Workbook for NonProfit Organizations. St. Paul, MN: Amherst H. Wilder Foundation. 